\title{
Morphogen gradient interpretation by a regulated trafficking step during ligand-receptor transduction
}

\author{
Jerome Jullien and John Gurdon ${ }^{1}$ \\ Wellcome Trust/Cancer Research UK Gurdon Institute, University of Cambridge, Henry Wellcome Building of Cancer and \\ Developmental Biology, Cambridge CB2 1QN, United Kingdom
}

\begin{abstract}
Morphogen gradients are important in early development, but how cells recognize their position in such a gradient is not well understood. Cells need to correctly interpret a morphogen concentration when the morphogen is no longer present in the extracellular medium. This memory of morphogen exposure is necessary for correct cell fate decisions in the changing morphogen gradient concentration in an embryo. Our results demonstrate that a previously unrecognized step in gradient interpretation is a temporal stop that arrests the progression of a ligand-receptor complex between internalization and lysosomal destruction. Signaling continues during this arrested progression, which constitutes the basis of memory of morphogen concentration. We show that prolonged signaling requires Dynamin-dependent internalization of the complex. Rab5QL- and Rab7QL-mediated increases in the speed of the endo-lysosomal progression do not affect memory. In contrast, memory is abolished by increasing the targeting of receptors to the lysosome through expression of the Smad7/Smurf2 ubiquitin ligase. We conclude that the basis for memory is the long-lasting residence of a signaling complex in the endo-lysosomal pathway. The regulated duration of this step helps to determine the choice of gene expression resulting from gradient interpretation.
\end{abstract}

[Keywords: Formation; gradient; interpretation; morphogen; Xenopus]

Supplemental material is available at http://www.genesdev.org.

Received February 25, 2005; revised version accepted August 26, 2005.

Morphogen gradients are important in early development. One single signaling event can generate several different cell fates in their correct spatial relationship. This is because cells can read their position in an extracellular gradient of morphogen molecules (Gurdon and Bourillot 2001). How cells interpret their position in a concentration gradient is not at all clear. We need to know how a cell makes one response to a particular concentration of morphogen and a completely different response to another concentration differing by only threefold (Green et al. 1992). But just as important is an understanding of what determines for how long a cell makes the same response. The main response of a cell to a morphogen is, as far as we know, the activation of downstream genes, usually encoding transcription factors. Because the concentration of morphogen around a cell will change with time from when a signaling process starts, it is essential that a cell continue to make the same response long enough for one response to a morphogen to prevail over other concentration-dependent responses that the same cell might make.

${ }^{1}$ Corresponding author.

E-MAIL j.gurdon@gurdon.cam.ac.uk; FAX 44-1223-334185.

Article published online ahead of print. Article and publication date are at http://www.genesdev.org/cgi/doi/10.1101/gad.341605.
The simplest mechanism for determining the duration of a morphogen response is for a cell to change its response continuously in direct proportion to the extracellular morphogen concentration. But we know this does not happen. In the case of activin, cells ratchet up their response as the morphogen concentration increases, but if this concentration decreases, a cell remembers for several hours the highest concentration to which it has been exposed (Dyson and Gurdon 1998). This memory ensures that a cell will make the same response to a concentration for long enough to achieve one particular outcome, and eventually to determine one cell fate. In embryos, such a memory of morphogen seems to be an essential part of morphogen gradient interpretation. The time when cells receive an effective concentration of morphogen and the time when cells activate downstream genes may, indeed, be separated by several hours. For example, activin mRNA is first detected in the embryo at stage 8-9, when Smad2 phosphorylation is also first seen (Lee et al. 2001; Schohl and Fagotto 2002; Piepenburg et al. 2004). Nevertheless, strong Xbra transcription induced by activin occurs only at stage 10-10.5, namely, 3-4 h later (Dyson and Gurdon 1998; Bourillot et al. 2002; Piepenburg et al. 2004). The existence of such a memory in morphogen gradient interpretation has also been demonstrated in mice, where cells in the limb bud need to 
memorize Shh exposure to correctly change their fate later on (Harfe et al. 2004).

A basic sequence of TGF- $\beta$ signaling events was first established in cultured cells (Shi and Massague 2003). During activin signaling, the extracellular ligand first binds to its type II receptor, enabling a type I receptor to join the complex. The type II receptor phosphorylates the type I receptor, which, in turn, phosphorylates Smad2, and this associates with Smad4 to enter the nucleus and activate the promoter of downstream genes. In these cultured cells, TGF- $\beta$ receptors are internalized in a ligand-independent manner (Ehrlich et al. 2001; Di Guglielmo et al. 2003). Smad2 activation seems to occur mainly from within the cell, at the level of the endosome, where accessory proteins such as SARA or cPML favor the association of Smad2 with TGF- $\beta$ receptors (Hayes et al. 2002; Di Guglielmo et al. 2003; Lin et al. 2004). It is not known whether a memory of TGF- $\beta$ treatment exists in cultured cells. Available data seem to indicate that after both continuous or pulse treatment of cultured cells with TGF- $\beta$, the level of phosphorylated Smad2 peaks between 0.5 and $1 \mathrm{~h}$ after ligand addition and decreases thereafter (Lo and Massague 1999; Di Guglielmo et al. 2003). This suggests that cultured cells do not show the memory of ligand exposure characteristic of embryonic cells.

Previous work on the activin treatment of Xenopus embryo cells has established the following (Dyson and Gurdon 1998; Bourillot et al. 2002). First, 50\% of the activin molecules bound to animal cap cells remain associated with these cells for at least $5 \mathrm{~h}$. Second, the phosphorylation and nuclear translocation of Smad2, the intracellular transduction molecule for activin, continue for at least $4 \mathrm{~h}$ after a 10-min activin pulse. Third, the pool of activated Smad2 formed at the time of activin exposure is not stable enough to account for the memory, since this initial pool is degraded with a 1-h half-life. Fourth, the memory depends on a continuing serine/threonine kinase activity.

The mechanism by which memory of activin exposure is maintained for the desired amount of time in Xenopus embryonic cells is completely obscure. Here we have followed the intracellular fate of a ligand/receptor complex, and we show that the critical step in determining the duration of signaling is the time spent by these complexes in the endo-lysosomal pathway of embryonic cells. Endocytosis is necessary to generate signaling complexes, whereas delayed targeting to the lysosome ensures the persistence of signaling by such internalized complexes. Our results, therefore, introduce the concept of a regulated step in an intracellular morphogen response pathway. They also provide a mechanistic understanding of how the memory of morphogen concentration selects a specific gene response.

\section{Results}

Memory of activin exposure requires continuous receptor signaling

Our hypothesis is that the memory of activin concentration depends on a long-lasting pool of activated recep- tors. We first ask whether the stability of occupied receptors is consistent with this idea. The procedure by which we test cell memory of activin treatment is shown in Figure 1A. Dissociated cells are incubated for a short period of time in the presence of activin and then washed extensively to remove all unbound ligand. As seen in Figure 1B, cells continue to display the same response to activin for at least $5 \mathrm{~h}$ after a 10 -min treatment. We know from previous work that animal cap cells are competent to activate mesodermal genes in response to activin treatment only after stage 10 (Bourillot et al. 2002; Piepenburg et al. 2004). So the observed gene induction in our experiment implies memory for activin treatment of at least 3-4 h, namely, for the time separating activin treatment from gene transcription.

To determine the stability of activated receptors, we have labeled the cell surface receptor ActRII-B with biotin and then followed the fate of the labeled receptors for a few hours. In Figure 1C, we see that labeled receptors remain associated with cells for at least $3 \mathrm{~h}$. This is true for receptors initially bound to activin, since the activin treatment we used was sufficient for ligand to be bound to $>90 \%$ of receptors (Dyson and Gurdon 1998). Therefore, the ligand-bound type II receptors are sufficiently stable to be consistent with our hypothesis. We have not been able to follow the fate of ActRIB in a similar way. As an alternative, we have asked whether cell memory requires the continuing serine/threonine kinase activity of ActRIB. To do so, we have taken advantage of a recently described specific ActRIB kinase inhibitor, SB431542 (Inman et al. 2002). When added to animal cap cells, this drug completely inhibits gene induction in response to an activin pulse (Fig. 1D, lane 3). The serine/ threonine activity of type I activin receptors is required for a long time after the activin pulse, since SB431542 largely suppresses gene induction even when added $2 \mathrm{~h}$ after the activin pulse (Fig. 1D, lane 5). Altogether these data confirm that activin receptor signaling activity is needed over the 3-4-h period separating activin pulse and gene transcription.

Two explanations could account for this maintained signaling: The activin pulse could generate a long-lasting supply of any intracellular component of the activin transduction pathway. Alternatively, the activin pulse could promote the production by the receiving cells of a secreted factor such as activin, nodals, or Veg1, leading to a later activation of ActRIB in the same cell. To rule out the possibility of a secondary production of activin as a basis for memory, we have made use of Follistatin, which prevents the association of activin with ActRII (Marchant et al. 1998). When recombinant Follistatin is added at the same time as the activin pulse, gene induction is indeed inhibited (Fig. 1E, lane 3). In contrast, when Follistatin is added immediately after the activin pulse, it does not affect memory of activin exposure, since gene induction takes place normally under those conditions (Fig. 1E, lane 4). Since all activin molecules secreted after the activin pulse would be neutralized by Follistatin, this experiment demonstrates that secondary secretion of activin is not required for cell memory of 
Jullien and Gurdon

A

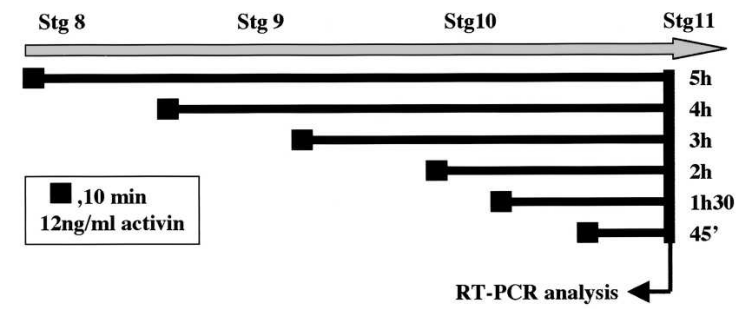

E

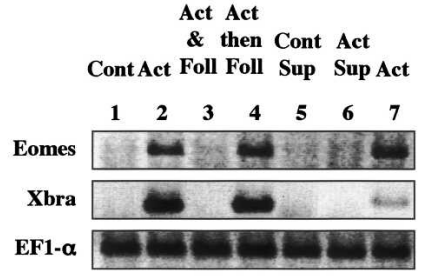

$\mathbf{F}$
C Time of chase : $\quad 0 \quad 30, \quad 1$ h $\quad 3 h$

D

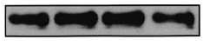

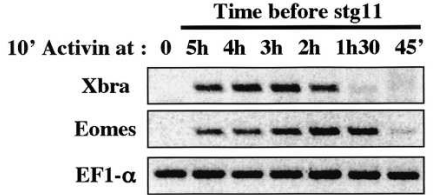

Figure 1. Memory of activin concentration requires continuing serine-threonine kinase activity. (A) Experimental design for testing memory of activin treatment. (B) Memory of activin treatment is fully maintained for at least $5 \mathrm{~h}$ : RT-PCR analysis of the experiment carried out as in $A$. $(C)$ Cell surface-derived type II activin receptors, whether occupied or not, are stable for at least 3 h. Animal cap cells expressing ActRII-Myc were incubated for $30 \mathrm{~min}$ with $100 \mathrm{ng} / \mathrm{mL}$ activin to fill all receptors. Dissociated cells were cell surface biotinylated. Up to this stage, cells were kept at $4^{\circ} \mathrm{C}$ to prevent receptor internalization. Cells were then cultured for the times shown, when biotinylated proteins were precipitated with streptavidin and analyzed by Western blotting. $(D)$ Long-lasting serine/threonine kinase activity of activin type I receptors is required for memory of activin exposure. (Lane 2) A 10-min activin treatment is followed by washing and culture as in A. Ten micromolar SB431542 (SB, specific inhibitor of type I receptor kinases) is added after activin treatment for the whole $4 \mathrm{~h}$ (lane 3), for the first $2 \mathrm{~h}$ (lane 4), or for the last $2 \mathrm{~h}$ (lane 5). (E) A secondary secretion of mesoderm-inducing factor is not required for the memory of activin exposure. Stage 8 animal cap cells were either given no activin (lane 1) or a 10-min $12 \mathrm{ng} / \mathrm{mL}$ activin pulse (lanes 2-4). One sample was also given Follistatin (500 ng/mL) during and after the activin pulse (lane 3), or immediately after the activin pulse (lane 4). Four hours after the activin pulse, cells were collected for RT-PCR analysis. Another set of animal caps at stage 9 was treated for $2 \mathrm{~h}$ with the supernatant from samples 1 and 2 (lanes 5,6) or with $12 \mathrm{ng} / \mathrm{mL}$ activin for $2 \mathrm{~h}$ (lane 7). (F) Memory of activin exposure does not involve a relay by nodals. Control or Cerberus-injected (0.6 ng/embryo) animal cap cells were submitted to a 4-h activin memory test (as in $A)$. (Lanes 5,6) Xnr1 (0.3 ng/embryo) or Cerberus and Xnr1 (0.3 and $0.6 \mathrm{ng}$ per embryo, respectively) injected embryos were used as a control for the functional inhibition of Xnrl by Cerberus in this test.

activin exposure. Nodals are TGF- $\beta$-related factors whose expression is activated by activin and could therefore also act as a relay after an activin pulse (Osada et al. 2000). To exclude this possibility, we have tested memory of activin exposure in Cerberus mRNA injected animal cap cells. Cerberus is a secreted TGF- $\beta$ antagonist that specifically inhibits nodals but not activin (Piccolo et al. 1999). As shown in Figure 1F, Cerberus injection inhibits Xnrl-mediated mesodermal gene induction in the embryo (cf. lanes 5 and 6). But Cerberus expression does not interfere with memory of activin exposure (Fig. $1 F$, lanes 2,4$)$. Therefore, we conclude that secondary secretion of nodals is not responsible for memory of activin exposure.

We have also tested the culture medium taken from cells incubated for $4 \mathrm{~h}$ after an activin pulse. As shown in
Figure 1E, when added for $2 \mathrm{~h}$ to new animal cap cells, such a cell culture medium is not able to induce mesodermal genes (lane 6), although cells are competent to respond to added activin at this time (lane 7). This observation also excludes the possibility that a factor not sensitive to Follistatin or Cerberus inhibition is secreted by animal cap cells to maintain ActRIB activity.

We conclude that the stability of a ligand ActRII complex and the duration of ActRIB signaling are consistent with these forming the basis of memory.

\section{Activin receptors are internalized at the time when memory of activin concentration is established}

Our conclusion so far is that memory of activin exposure relies on the direct production, upon activin binding, of 
a pool of receptors able to signal for a long period. How is such a stable signaling complex generated? Work on cell lines indicates that receptors from the TGF- $\beta$ family of ligands are internalized from the plasma membrane to the early endosome of cells, leading either to recycling back to the plasma membrane or to lysosomal degradation. Whether this trafficking step is essential for signal transduction is more controversial (Lu et al. 2002; Di Guglielmo et al. 2003). In the light of this relationship between trafficking and signaling in cell lines, we have analyzed the involvement of receptor endocytic trafficking in cell fate determination by activin in normal Xenopus embryonic cells.

We have first asked if the active receptors are located inside embryonic cells. For this, we have used receptor forms with an epitope tag inserted in their extracellular domain in order to label cell surface receptors of live animal cap cells by fluorescently labeled anti-tag antibodies. The validity of such an approach for tracking TGF- $\beta$ receptor trafficking from the cell surface has been extensively demonstrated in cells lines (e.g., see Di Guglielmo et al. 2003). After $4^{\circ} \mathrm{C}$ labeling, receptors are, as expected, colocalized with GFP-GPI at the plasma membrane of animal cap cells (Fig. 2A,B, 0 min, arrow). Within $30 \mathrm{~min}$ at $23^{\circ} \mathrm{C}$, both ActRIB and ActRII are internalized as shown by loss of colocalization of receptors and GFP-GPI and the subsequent appearance of labeled receptors in intracellular vesicles (Fig. 2A,B, $30 \mathrm{~min}$, arrows). Internalized receptors are targeted to the early endosome, since a strong colocalization of labeled receptors with rab5-GFP is observed (Fig. 2A,B, $30 \mathrm{~min}$, arrowheads). With longer incubation times receptors seem to move out from the early endosome (loss of receptor colocalization with rab5-GFP) but do not recycle back to the plasma membrane (no colocalization with GFP-GPI) (Fig. 2A,B, 4 h, arrowheads). Similar observations are made when activin $(100 \mathrm{ng} / \mathrm{mL})$ is added to the extracellular medium to ensure that almost all receptors are occupied by ligand (data not shown). When monitored in the same cell ActRIB and ActRII show extensive colocalization at all steps of endocytic trafficking as demonstrated by the pink color resulting from the overlap of red (ActRII) and blue (ActRIB) channels (Fig. 2C, fourth column of enlarged area). The last column of Figure 2C indicates that these colocalized receptors are found in endosomes from $15 \mathrm{~min}$ to $1 \mathrm{~h}$ after internalization as shown by the white color resulting from the overlap of all three labels (ActRII, red; ActRIB, blue; and rab5-GFP, green channels).

We conclude that receptor complexes are present in the endocytic pathway of Xenopus animal cap cells when memory is established.

\section{Receptor internalization is necessary for cell fate determination in response to activin}

Since receptors are internalized, we have tested whether receptor-ligand trafficking is required for cell fate determination by activin. To do so, we have used the mutant protein Dynamin K44E, which can act as a dominant- negative inhibitor of endogenous Dynamin and hence can lead to a defect of internalization from the plasma membrane (van der Bliek et al. 1993). Dynamin mutants have been shown to inhibit internalization through both clathrin-dependent and -independent pathways (Henley et al. 1998). We have first checked that Dynamin K44E does inhibit receptor internalization when expressed in Xenopus animal cap cells. As shown in Figure 3A, the injection of Dynamin K44E inhibits transferrin internalization in Xenopus animal cap cells, indicating that the coated pit internalization pathway is prevented under this condition. Figure $3 \mathrm{~A}$ also shows that Dynamin K44E-injected cells present cell surface accumulation of ActRIB and ActRII (see Fig. 3 legend for details). This observation indicates that Dynamin K44E expression also prevents internalization of both activin type I and type II receptors.

We were then able to test whether this Dynamin K44E-mediated inhibition of receptor internalization interferes with cells' response to activin. Animal cap cells from stage 8 embryos injected or not with Dynamin K44E mRNA were collected, treated for $10 \mathrm{~min}$ with activin, washed, and incubated for $4 \mathrm{~h}$ at $23^{\circ} \mathrm{C}$ (until stage 10.5). mRNA was then extracted from the animal cap cells, and expression of the activin-induced genes Xbra and Eomes was evaluated by RT-PCR. Dynamin K44E injection inhibits Xbra and Eomes expression in response to activin as compared with control embryos (Fig. 3B,C). The same inhibition is seen when internalization of receptors is prevented by treatment of animal cap cells with the drug PAO (data not shown). These observations demonstrate that receptor internalization is necessary to obtain gene induction in response to activin in Xenopus animal cap cells.

\section{Ligand internalization is necessary for cell fate determination in response to activin}

We next asked whether ligand internalization is necessary for activin signaling. To do so, we designed an experiment that allows us to test the same ligand either free in solution (and hence internalization competent) or immobilized on beads (and thus internalization incompetent). An activin solution is biotinylated and purified (b-activin). b-Activin is then divided by streptavidin bead precipitation into an immobilized fraction (b-activin bound to streptavidin beads) and a nonimmobilized fraction (supernatant of streptavidin precipitation) (Fig. 4A). Then, the three preparations of activin are used to treat dissociated animal cap cells, the nonimmobilized fraction serving as a control for streptavidin precipitation efficiency. RT-PCR analysis is then carried out to test gene induction in response to the various treatments (Fig. 4B). As a free ligand, b-activin is as efficient as normal activin in inducing Xbra and Eomes (Fig. 4B, cf. tracks 2 and 3). Streptavidin precipitation greatly depletes b-activin solution of Xbra/Eomes-inducing activity (Fig. 4B, cf. tracks 3 and 7), whereas nonbiotinylated activin is, as expected, not affected by this precipitation (Fig. 4B, cf. tracks 2 and 6). The Xbra/Eomes-inducing 

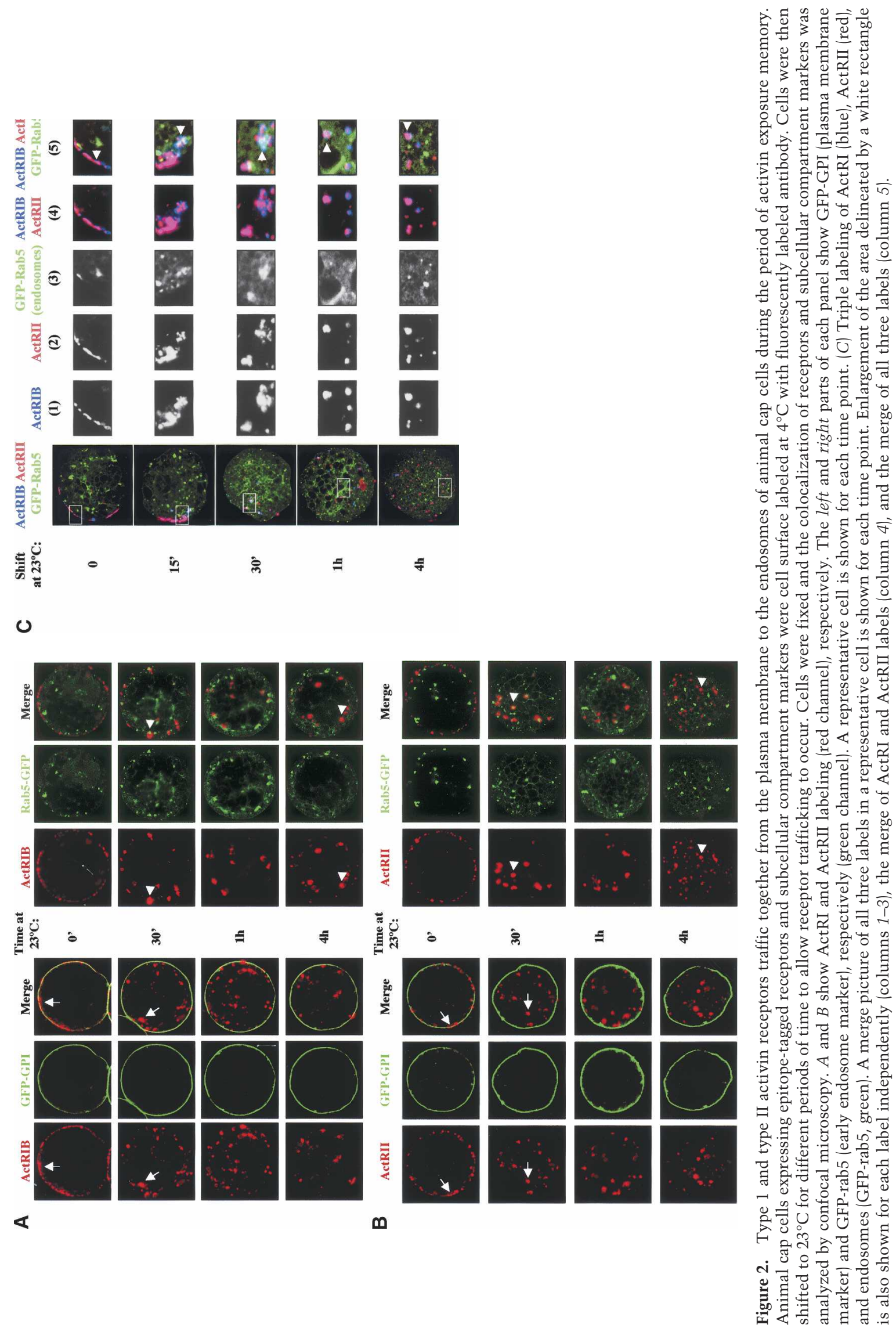
A

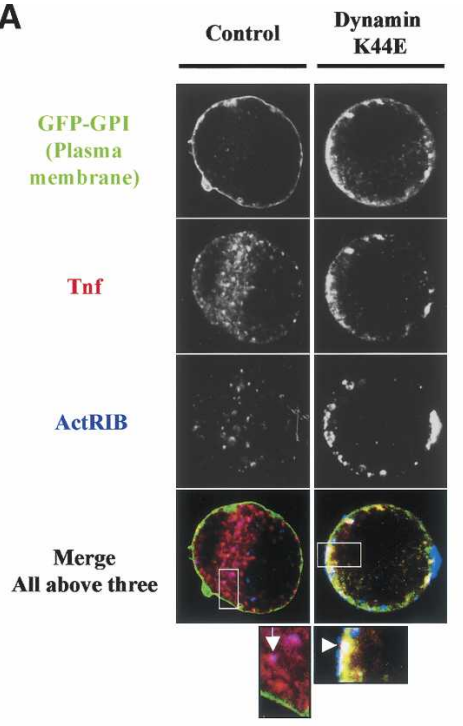

B

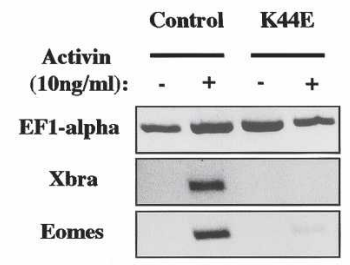

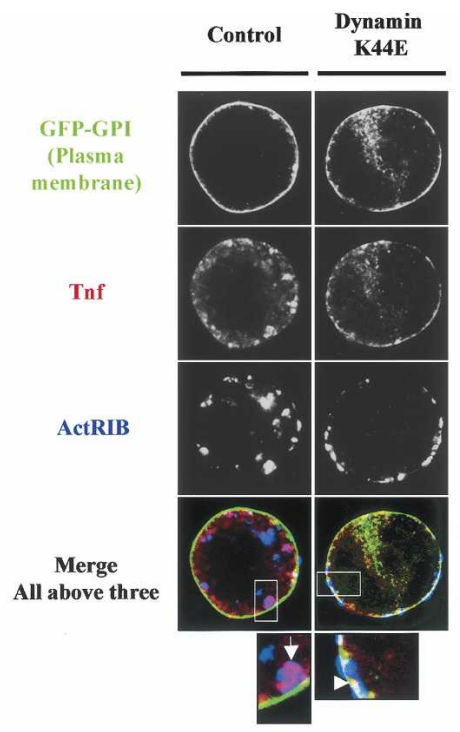

C

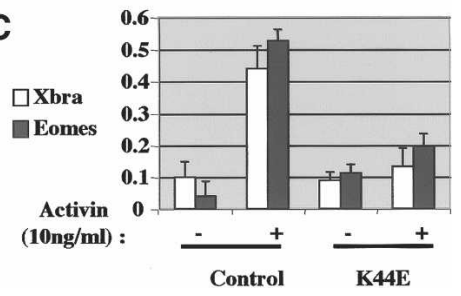

Figure 3. Dynamin-dependent internalization of activin receptors is necessary for gene induction in response to activin. Embryos were injected with Transferrin receptor and GFP-GPI mRNAs together with the indicated combination of Dynamin K44E, HA-ActRI, and Myc-ActRIIB mRNAs. Animal cap cells from stage 8 embryos were collected, dissociated, and separated into two parts: $(A)$ One-half of the cells were labeled at $4^{\circ} \mathrm{C}$ with fluorescent anti-HA or anti-Myc antibody to label cell surface HA-ActRI or Myc-ActRIIB, respectively. Cells were then shifted at $45 \mathrm{~min}$ to allow receptor trafficking to occur. During the $23^{\circ} \mathrm{C}$ incubation, Texas red-transferrin was added to the medium in order to follow receptor-mediated internalization via the coated-pit pathway (which is the internalization pathway of the transferrin-transferrin receptor complex). Following incubation, cells were fixed and receptor localization was analyzed by confocal microscopy. The fluorescence in each channel is shown independently (GFP-GPI identifies the plasma membrane of the cell [green channel], Tnf shows rhodamine-transferrin localization [red channel]; ActRI and ActRII localizations are shown in the left and right panels, respectively [blue channel]). A merge panel of all three labels is also shown, together with an enlargement of the area delineated by the white rectangle. In the merge picture of control cells, the pink color indicates colocalization of transferrin and activin receptors. These colocalized receptors (arrows) are in vesicles inside the cells, since they are distinct from the plasma membrane marker (green). In contrast, in Dynamin K44E-injected cells,

ActR and transferrin receptors remain at the plasma membrane as shown by the white color resulting from the overlap of ActR (blue), transferrin (red), and plasma membrane (green) labels (arrowheads). (B) The second half of the cell preparation was treated or not for $10 \mathrm{~min}$ with $12 \mathrm{ng} / \mathrm{mL}$ activin, washed to remove excess activin, and incubated for a further $4 \mathrm{~h}$. RNAs were then extracted from the cells and gene induction was monitored by RT-PCR. (C) Quantification of RT-PCR gels (mean of three independent experiments).

activity that is removed from b-activin solution by steptavidin precipitation can be attributed to the removal of active b-activin molecules bound to the streptavidin beads. But these molecules, active as free ligand, are no longer active when immobilized on beads as shown by the lack of gene induction by this fraction (Fig. 4B, track 5 ). We have checked that streptavidin-bead-bound activin is able to interact with either solubilized ActRII receptors or receptors on live cells (Supplementary Fig. S1). Moreover, activin internalization is confirmed by confocal analysis of cell labeled with biotinylated activin (Fig. 4C). These data suggest that internalization of activin itself is necessary for gene induction.

We conclude from these results that activin exposure is memorized by embryonic cells in the form of an internalized activin-activin receptor signaling complex ("memory complex"). This identifies an internalized activin/activin receptor complex as a necessary component of morphogen gradient interpretation.

The duration of signaling by the memory complex is determined by its rate of progression through the endo-lysosomal pathway

The next question we addressed is how stability of the memory complex and hence its duration of signaling is achieved. In cultured cells, membrane receptor stability is largely regulated by lysosomal degradation, which follows the sequential transport of receptor from the plasma membrane to sorting endosomes to multivesicular bodies (MVBs) and ultimately to lysosomes (Raiborg et al. 2003; see also Fig. 7B, below). In animal cap cells, stability of internalized activin receptors is also dependent on lysosomal degradation (Supplementary Fig. S3). During transport, targeting signals are added to receptors, allowing their sorting to the correct trafficking pathways. For example, the addition of ubiquitin to a receptor cytoplasmic tail directs this receptor to the internal membrane of the MVBs (Raiborg et al. 2003). Sorting to the MVB's internal membrane ends receptor signaling by isolating receptors from the cytosol.

We first reasoned that if the stability of the memory complex is related to slow receptor transport to the lysosome, its presence in the cytosol and hence its duration of signaling will be affected by any modification of the rate of transport in this pathway. To test this idea, we used the mutant proteins Rab5QL and Rab7QL, which accelerate trafficking from plasma membrane to sorting endosome and MVBs to lysosomes, respectively (see Fig. 7B [below], steps 1 and 5). Both of these mutant Rabs increase the rate of lysosomal degradation of membrane proteins in Xenopus oocytes (Mukhopadhyay et al. 
Jullien and Gurdon

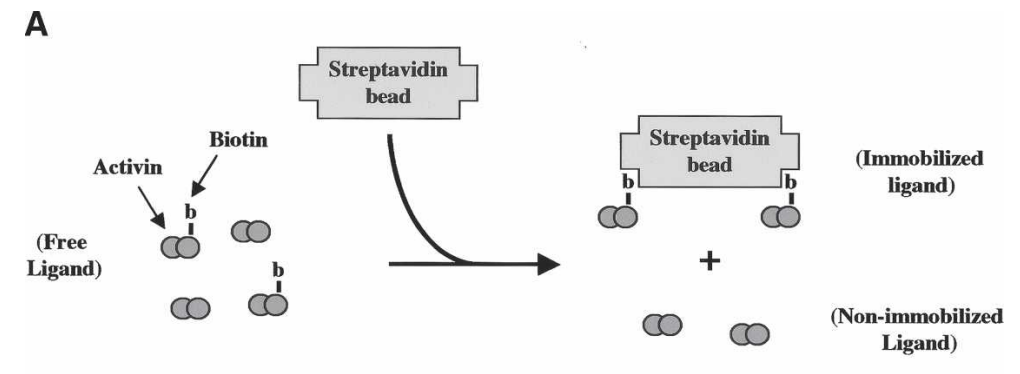

Figure 4. Activin internalization is necessary for gene induction in response to activin. $(A)$ Experimental design. (B) RT-PCR analysis of gene induction with immobilized activin: Standard (Act) or biotinylated (b-Act) activin solutions are used for treatment of animal cap cells. Each solution is tested as free, immobilized, or nonimmobilized fractions as shown in $A$. Cells are incubated for $2 \mathrm{~h}$ in the presence of the indicated fractions. RNA is then extracted from the cells, and gene induction is monitored by RT-PCR. (C) Biotinylated activin internalization in animal cap cells. Cells were sequentially labeled with biotinylated activin and fluorescently labeled streptavidin at $4^{\circ} \mathrm{C}$. Cell surface ActRII was then labeled as in Figure 2. Following cell surface labeling of receptor and activin, animal cap cells were shifted or not to $23^{\circ} \mathrm{C}$ to

B allow internalization to occur.

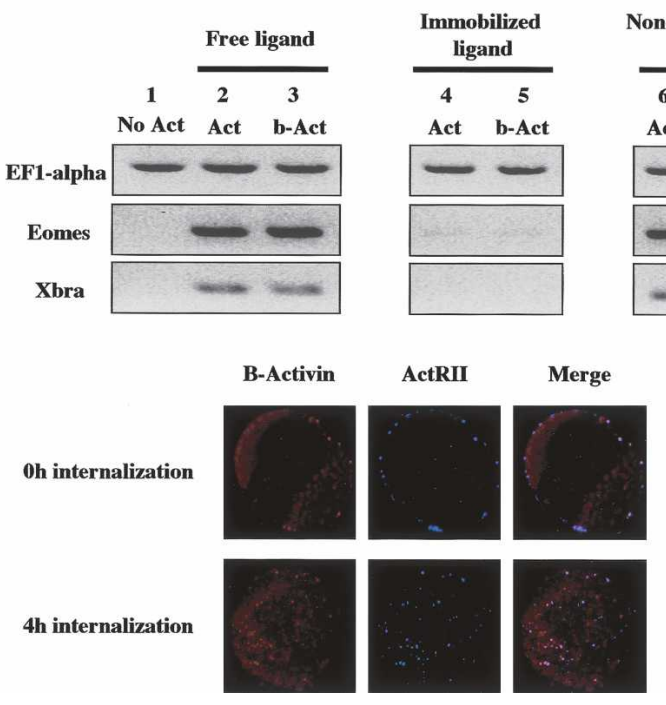

1997). Figure 5A shows that activin memory is not affected by an increase in the overall speed of lysosomal trafficking, since none of the Rab mutants affect gene response $4 \mathrm{~h}$ after an activin pulse. Even the coinjection of Rab5QL and Rab7QL, whose actions are additive in increasing the lysosomal degradation of membrane proteins in Xenopus, has no effect on cell memory (Fig. 5A). We conclude from these results that during the period when activin memory persists, the memory complex does not enter the degradation pathway, even if the Rabssensitive stages are accelerated. To confirm this, we have overexpressed activin receptors by mRNA injection in the embryo. In that way, ligand-independent activation occurs continuously, and activated receptors are present all along the endocytic pathway. In this case, the Rab mutant-mediated acceleration of lysosomal trafficking decreases gene response (Fig. 5B). This observation shows that, when activated receptors are supplied continuously, their passage to the lysosome is, indeed, accelerated by Rab mutants, a result that agrees with the idea that gene response is related to the duration of receptor-ligand dwell time in the cytosol.

These results led us to the proposal that the stability of the memory complex depends on a delay at one stage in the progression from cell membrane to lysosome, rather than on a continuous slow progression throughout. To test this, we have interfered with the timing of ubiquitin addition to receptors, by using the proteasome inhibitor MG132. This reagent inhibits the MVB-mediated sorting of monoubiquitinated receptors for degradation (van Kerkhof et al. 2001; Vecchione et al. 2003). Delayed progression by MG132 results in a significant increase in the strength of signaling (i.e., stability of the signaling complex) (Fig. 5C, $5 \mathrm{~h}$ ). In contrast to the effect of MG132, progress to the lysosome can be accelerated by Smurf2/Smad7, a specific type I TGF- $\beta$ receptor ubiquitin ligase complex (Di Guglielmo et al. 2003). This largely suppresses gene response (Fig. 5D). We see from these observations that memory complexes generated after an activin pulse are stable for 3-4 h because of an arrest in the progression toward ubiquitin-mediated lysosomal degradation.

These results establish the principle that it is the time spent by the memory complex in the endo-lysosomal pathway that determines the duration of signaling and hence the strength of response to a particular morphogen concentration.

\section{Formation of the memory complex is not required for gradient formation}

As the generation of a memory complex is involved in the interpretation of a morphogen gradient by embryonic cells, it might also participate in the formation of an extracellular morphogen gradient in the embryo. In Drosophila, it is not clear whether the spreading of morphogen from a source is dependent on endocytic trafficking (Entchev et al. 2000; Belenkaya et al. 2004). Having 
A

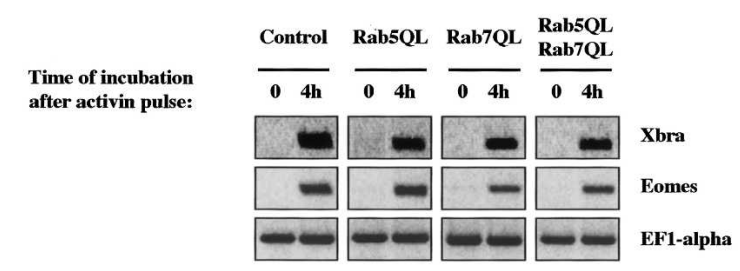

B

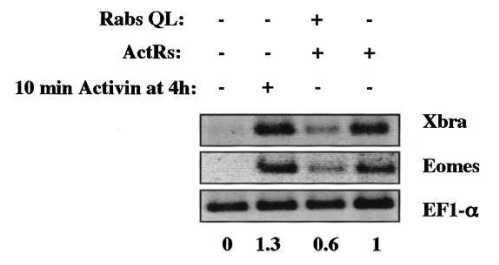

C

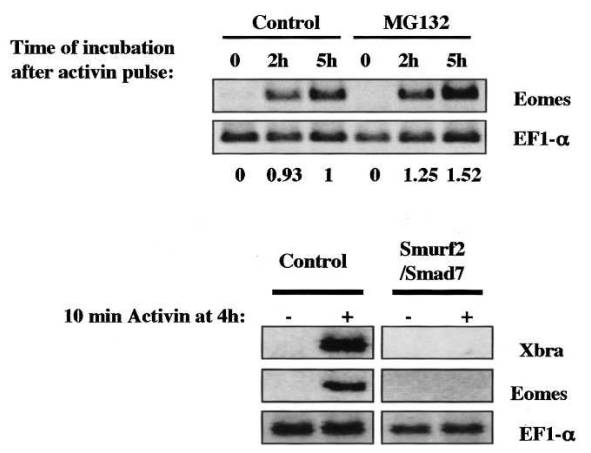

Figure 5. Receptor endocytic trafficking and cellular memory of activin exposure. Rate of transport to lysosome does not affect memory of activin exposure. (A) Two-cell-stage embryos were injected with the indicated combination of mRNAs encoding Rabs mutants known to increase the rate of transfer to lysosomes. Stage 8 animal cap cells were used for a 4-h memory test (as described in Fig. 1A). (B) Stage 8 animal cap cells from embryos injected with ActRI and ActRII, and with or without Rab5QL and Rab7QL mRNAs were dissociated and incubated until stage 11. The expression of mesodermal genes was then tested by RT-PCR. A decrease in mesodermal genes expression in the presence of Rab5QL and Rab7QL mRNAs was repeatedly observed. Values shown below the gel represent the Eomes signal normalized to the EF1- $\alpha$ level and were obtained by quantification of RT-PCR gel (mean value from two experiments). Delayed ubiquitin-mediated sorting of receptors to lysosomes allows memory of activin exposure. $(C)$ Stage 8 animal cap cells were treated or not with the proteasomal inhibitor MG132 (10 $\mu \mathrm{M})$ to inhibit the ubiquitin-mediated sorting of receptors for lysosomal degradation. Cells were then used for a 5- or 2-h memory test. Values shown below the gel are quantification of RT-PCR gel as in $B$. (D) Ubiquitin-mediated sorting of receptors for lysosomal degradation is increased by injection of two-cellstage embryos with mRNAs for Smad7 and Smurf2, the specific TGF- $\beta$ receptor ubiquitin ligase complex. Stage 8 animal cap cells were then used for a 4-h memory test. All panels represent RT-PCR analysis of mesodermal gene induction (Xbra/Eomes). EF1- $\alpha$ is used as a control for cDNA quantity in each sample.

shown that a Dynamin mutant inhibits activin receptor internalization in animal cap cells, we are now able to test whether receptor trafficking is involved in gradient formation in Xenopus embryonic tissue. We can also test the contribution of the endocytic pathway to the shaping of activin gradient by using the mutant protein Rab7QL.
We first tested activin propagation through internalization-deficient tissue in a three-dimensional (3D) test. To do so, we intercalated a Dynamin K44E-expressing animal-cap cell layer in between an activin-expressing vegetal pole (activin source) and a normal animal cap (receiving tissue) (Fig. 6A). After incubation of these sandwiches, we checked whether activin is able to move from the source to the receiving tissue. The spreading of activin is evaluated by in situ hybridization of sandwich sections using a probe specific for the gene Xbra. Control as well as Dynamin K44E sandwiches show similar Xbra labeling in receiving animal caps, indicating that activin is able to cross normal as well as internalization-deficient embryonic tissue (Fig. 6B). However, this $3 \mathrm{D}$ test is not accurate enough to allow us to detect small differences in the extent of activin spreading from its source.

We have therefore used a two-dimensional (2D) animal cap test in which activin-containing beads are grafted into the middle of an animal cap (Fig. 6C; T. Kinoshita, J. Jullien, and J.B. Gurdon, in prep.). Caps are then incubated between agarose-coated surfaces to allow propagation of activin from the beads to the surrounding embryonic tissue. After incubation, induction of the gene Xbra is detected by in situ hybridization and this allows the visualization of the area of the animal cap that has received a certain concentration of activin. A comparative analysis of bead-mediated Xbra induction in a complete normal embryo versus a cap explant shows that the spread of morphogen proceeds at the same rate in these two conditions, thereby validating the use of explant cultures (Supplementary Fig. S2).

We grafted cells from Dynamin K44E- or Rab7QL-injected animal caps to a position between activin-releasing beads and the outer area of the animal cap in which Xbra expression is normally seen. Both Dynamin K44Eand Rab7QL-expressing graft are seen to allow activin to propagate at the same rate as through the nongrafted surrounding area, as shown by the regular shape of the Xbra-expressing ring around the beads (Fig. 6D). This confirms that, in Xenopus embryos, the rate of propagation of activin is not dependent on internalization or on the endocytic processing of its receptors. This suggests that the activin gradient mainly forms by diffusion of the morphogen in the extracellular space. To confirm this finding, we used a Follistatin-expressing graft in a 2D test. A Follistatin graft positioned nearby the activinsecreting beads prevents the expression of Xbra outside the graft ("shadow," area without Xbra expression). Increasing the size of the Follistatin graft generates a corresponding increase of the shadow behind the graft (Fig. 6E).

Altogether, we conclude from these experiments that extracellular but not intracellular activin trafficking is required for gradient formation in embryonic tissue.

\section{Discussion}

The precise sensing of morphogen concentration by cells is crucial for correct cell fate patterning in embryonic development. A patterning event relies both on the pro- 
Figure 6. Endocytic trafficking and formation of an activin gradient. (A) Three-dimensional analysis of extracellular activin propagation. A rhodamine-dextran or Dynamin K44E and rhodamine-dextran-expressing animal cap cell layer is sandwiched between the vegetal pole of an embryo overexpressing activin (marked by a star) and an uninjected animal cap. In this context, the activin secreted by the vegetal tissue has to cross the intermediate layer in order to reach and activate Xbra in the uninjected animal cap. After $3 \mathrm{~h}$ of incubation, sandwiches were fixed and sectioned. Propagation of activin throughout the tissue was then measured by Xbra in situ hybridization. The effect of Dynamin K44E overexpression was determined by RT-PCR analysis on a fraction of dissociated cells used for formation of the intermediate layer (not shown). (B) In situ hybridization of sections of sandwiches after the 3D test. Red fluorescence indicates the position of rhodamine-dextran-injected cells in the intermediate layer. The star indicates the position of the activin-secreting tissue. (Right) The position of the intermediate layer is marked by a black line to allow better visualization of Xbra in situ hybridization. (C) 2D analysis of extracellular activin propagation: A bead loaded with activin is used to mimic an activin source. This bead is grafted to the center of an animal cap from a stage 8 embryo. At the same time, a graft from the animal cap of an embryo injected with an mRNA of interest together with the lineage marker rhodamine-dextran is placed next to the bead. Propagation of activin is then measured by in situ hybridization for the activin-induced gene Brachyury. $(D)$ Interfering with the intracellular route. The $2 \mathrm{D}$ test shown in $C$ is used to monitor activin gradient formation through embryonic tissue with modified internalization pathways (Dynamin K44E, no internalization; Rab7QL, increased lysosomal trafficking). The picture shows in situ hybridization of animal caps after the 2D test. Red fluorescence indicates the position of rhodamine-dextran-injected cells. The light-blue circle shows the position of the activin bead. (E) Interfering with the extracellular route. The $2 \mathrm{D}$ test shown in $C$ is used to monitor activin gradient formation through Follistatin-expressing embryonic tissue. From left to right are shown animal caps with increased areas devoid of Xbra expression distal to the Follistatin graft (red).
A
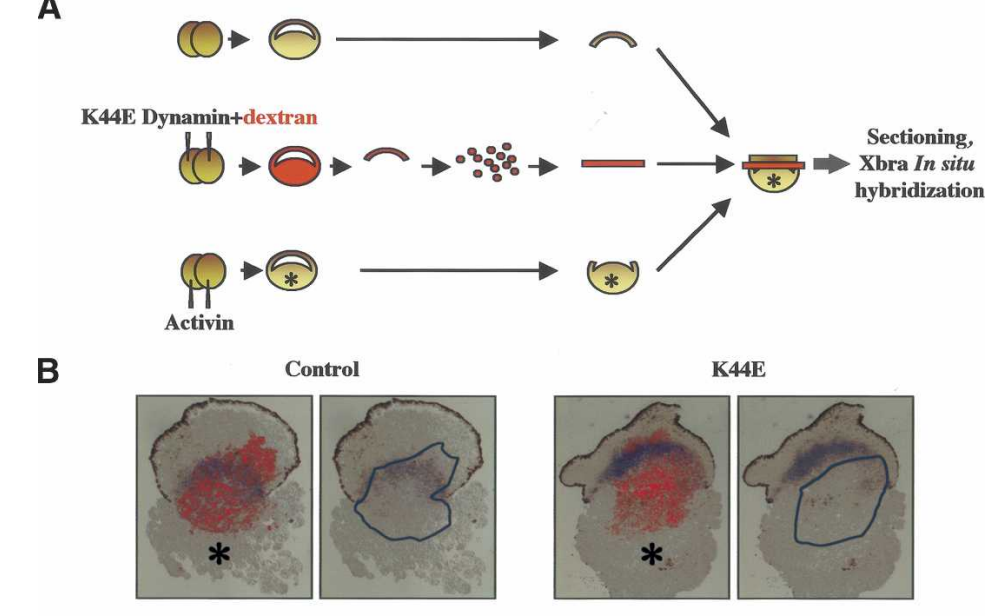

C

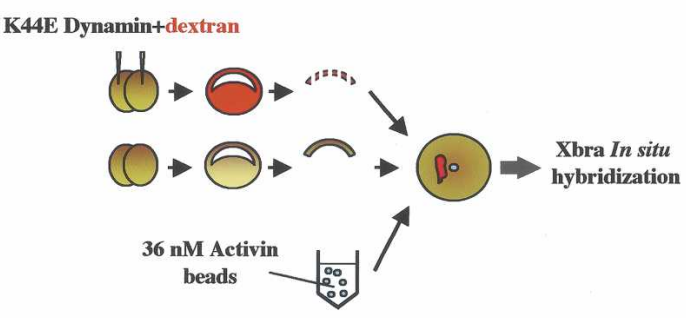

D

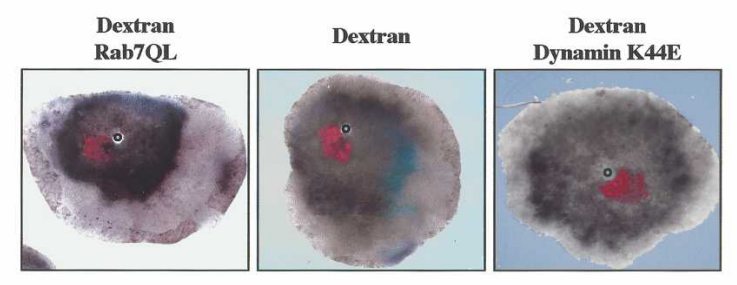

E

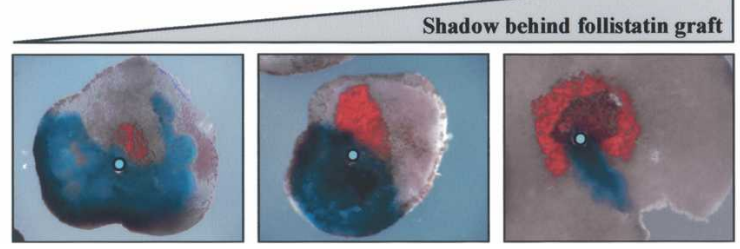

duction of a correct gradient of the morphogen in the embryo and on its precise interpretation by receiving cells. Here we have analyzed how the stability of a memory complex may influence both morphogen gradient interpretation and morphogen gradient formation at a time when cell fate decisions are taken in the early vertebrate embryo.

\section{An internalized receptor-ligand complex for prolonged signaling}

In cell lines the role of receptor internalization in TGF- $\beta$ signal transduction is not clear, since some studies find receptor-mediated internalization necessary and others do not (Lu et al. 2002; Di Guglielmo et al. 2003). It is possible that the discrepancy between these results comes from the fact that these cell lines cannot be tested for concentration-dependent responses to the TGF- $\beta$ family of ligands. In our results a complete abrogation of gene induction in response to activin is observed when receptor internalization is impaired in Xenopus embryonic cells. This indicates that efficient signaling is achieved only when receptors are accumulated intracellularly, in the endosomal compartment where we have seen internalized receptors. It is likely that Smad2 is, as in a cell line, targeted to endosomes via an adaptor protein such as SARA, consequently enhancing signaling from this compartment (Tsukazaki et al. 1998). But the fact that activin itself needs to be internalized for correct signaling suggests that localization of ligand to the en- 
dosomes is also required for a signaling step upstream from Smad2 activation. It is possible that the endosome also provides a suitable environment for activation of ActRIB by the activin-ActRII complex.

Signaling by other secreted factors such as the nerve growth factor (NGF) also show a requirement for both receptor and ligand internalization (Kuruvilla et al. 2004). During development of the peripheral nervous system, NGF is provided at the tip of axons and promotes survival of cell bodies located several cell diameters away. This situation provides another example in which memory is required: The information delivered at the axon tip has to be memorized for transport to the neuron body. This occurs by production of a stable active
NGF/NGF receptor complex that will still be able to signal after retrograde transport to the cell body. This mechanism of memory of ligand exposure may be used in different situations in development in which ligand exposure and efficient signaling to the cell nucleus are separated in time and/or space. We suggest that internalization of ligand provides a means to stabilize ligandreceptor interaction by preventing loss of ligand in the extracellular medium.

Our data are compatible with a model in which memory is based on an active complex of activin and its type I and type II receptors (Fig. 7B). The observation by confocal analysis of a close association of cell surface-derived ActRIB and ActRII fits well with this proposal (Fig. 2).
A
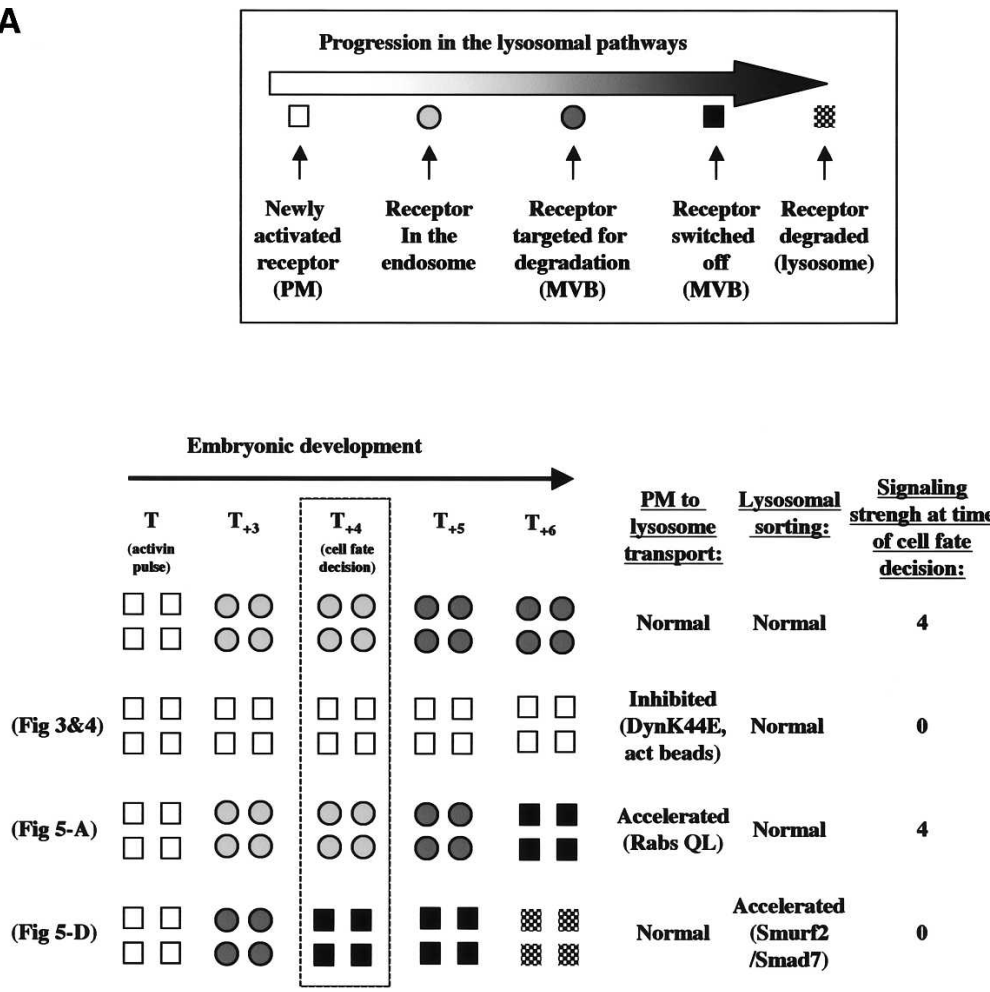

B

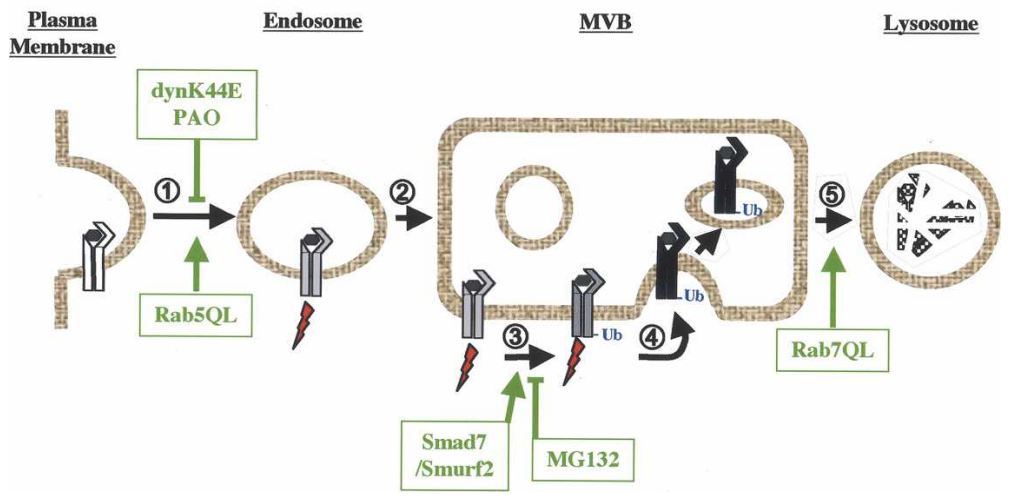

Figure 7. Model of memory complex signaling during morphogen gradient interpretation. $(A)$ Fate of memory complex in different endocytic trafficking conditions. (Top) Colors from white to black indicate the receptor position in the lysosomal pathway. Receptor shape symbolizes whether an activated receptor is able to signal (circle) or not (square). The crucial parameter for cell fate decision is the number of signaling complexes present in a cell at the time of cell fate decision (number in "signaling strength" column). A pool of receptors is activated at the plasma membrane (PM) during an activin pulse. (First row) In normal endocytic trafficking conditions, most of the receptors formed during an activin pulse are still in the endosome or MVBs external membrane at the time of cell fate decision. This allows a continuing high signaling strength, thereby accounting for activin memory. (Second row) When receptors are prevented from internalization, they remain at the plasma membrane in a nonsignaling status. (Third row) When the rate of transport to the lysosome is increased, signaling strength at the time of cell fate decision is not affected, since receptors are not targeted for degradation until this time. (Fourth row) When ubiquitin-mediated targeting of receptors for lysosomal degradation is increased, receptors are more quickly degraded and fewer receptors are still able to signal at the time of cell fate decision. (B) Trafficking and signaling of activin-activin receptor memory complexes. Activin (dark hexagon) binds to its type II receptors at the plasma membrane, allowing recruitment of type I activin receptor to form the memory complex. Cell surface memory complexes are not able to induce gene transcription. The memory complex has to move to endosomes to produce effective signaling (red lightning). Memory is ended by receptor internalization to the internal membrane of MVBs. Green arrows and green lines indicate proteins or drugs used in this study to inhibit or potentiate given steps in memory complex trafficking from the plasma membrane. Dynamin K44E inhibits receptor internalization to the endosome. Rab5QL and Rab7QL increase the rate of transport from plasma membrane to early endosome and from MVBs to lysosome, respectively. Ubiquitin-mediated sorting of receptors to lysosome is inhibited by MG132 and promoted by the Smurf2/Smad7 complex, respectively. 
Memory of activin exposure is determined by kinetics of activin receptor endo-lysosomal trafficking

The process by which we believe a morphogen gradient is interpreted by embryonic cells in the particular case of activin is as follows. An increasing number of receptors is bound as the supply of extracellular ligand goes up. The steady-state concentration of activated Smad2 in the nucleus is proportional to the maximum number of ligand-bound receptors (Bourillot et al. 2002). We show that this number of activated receptors persists for several hours even when extracellular ligand is reduced. The choice of downstream gene activation, and hence of cell fate decision, is determined not only by the highest level of receptor occupancy reached but, crucially, also by the length of time for which this level of signaling persists (memory). This is because a short period of any kind of gene expression will not give sufficient gene product to establish any one cell fate. Our results presented here show that the length of time for which a particular strength of signal persists depends on the time spent by the ligand/receptor memory complex in the endo-lysosomal pathway of a cell. It is this that maintains the intracellular concentration of active Smad2 at its highest level, and that therefore determines the choice of cell fate resulting from gradient interpretation. Work by Di Guglielmo et al. (2003) supports the hypothesis that endosomes are the main signaling compartment for TGF- $\beta$ receptors. The proposed explanation for the increased signaling ability of receptors in that compartment is that they are protected from degradation. This observation fits well with the observed stability of the memory complex observed in the present study. Di Guglielmo et al. also present evidence that degradation of the receptors requires entry into a different trafficking pathway involving the smad7/Smurf2 complex, a situation we also observe. The model proposed in cell lines states that receptors enter in either of the two trafficking pathways (signaling endosome vs. degradative pathway) at the level of the plasma membrane. Since we do not observe internalized receptors trafficking back to the plasma membrane, we propose that this transition from the signaling to the degradative pathways occurs intracellularly, possibly at the level of the multivesicular body (see Fig. 7 and below). Our results extend the conclusions from work on cell lines to events that take place when normal embryos make cell fate decisions.

According to our model, the stability of the signaling complex is crucial for interpretation of morphogen concentration. Figure 7A summarizes the different levels at which the amount of signaling complex is regulated in a cell. The memory test allows us to generate a pool of receptors moving synchronously along the lysosomal pathway. Only those ligand-receptor complexes that actively signal when cells are competent to transcribe genes determine the final cell fate decision. This excludes activated receptors at the plasma membrane and in the internal vesicles of MVBs (see Fig. 7B). Thus, modifications in production (internalization), or in removal (lysosomal targeting), of signaling receptors from the endosomal pathway can interfere with the number of complexes efficiently signaling in the cell at the time of the cell fate decision (Fig. 7A). The observed stability of the signaling complex implies that cells interpret a morphogen gradient by integrating all the signals they have received before the cell fate decision rather than by responding to the latest morphogen gradient concentration around them. The accumulated signaling complex then determines the steady-state accumulation of activated Smad2 in the nucleus, which will, in turn, determine the appropriate gene transcription response (Dyson and Gurdon 1998; Bourillot et al. 2002).

Our results show that stability of the memory complex is normally achieved by a delayed receptor targeting to lysosomes. This step is regulated and identifies a new level of morphogen gradient interpretation. Mechanistically, this provides an explanation for the long-lasting memory of morphogen gradient exposure. Involvement of the endo-lysosomal pathway in the regulation of morphogen interpretation has recently been suggested in zebrafish, where the protein dpr2 was shown to regulate nodal signaling in the embryo (Zhang et al. 2004). In cultured cells, this protein localizes to lysosomes and decreases the stability of the TGF- $\beta$ receptor ALK5.

\section{Receptor endocytic trafficking is not involved in activin gradient formation}

Equally important for patterning mechanisms by a morphogen is the shape and extent of the morphogen gradient. In the Drosophila wing, it has been proposed that morphogen gradients arise by serial rounds of endocytosis/exocytosis of the morphogen (transcytosis) (Entchev et al. 2000; Dubois et al. 2001; Seto et al. 2002; Zhu and Scott 2004). Previous work in Xenopus suggests that morphogen gradients form by simple extracellular diffusion in this system (Jones et al. 1996; McDowell et al. 1997). This conclusion was partly based on the ability of this TGF- $\beta$ factor to cross a layer devoid of TGF- $\beta$ receptors. In embryos it is likely that a morphogen gradient forms throughout a tissue of responsive cells. We have extended earlier analysis by comparing the spreading of a gradient through normal versus internalization-deficient responsive tissue. Our data show that gradient spreading is independent of the status of the endocytic pathway. The propagation of morphogen by transcytosis, as observed in Drosophila, is thus excluded in Xenopus. This correlates well with the fact that we do not see a return of activin receptors to the plasma membrane once internalized, suggesting that transcytosis is not occurring in animal cap cells (Fig. 2). In Drosophila, morphogen transport by the way of long cellular processes linking a source to receiving cells (cytonemes) has also been proposed (Ramirez-Weber and Kornberg 1999). This process is also unlikely to occur in Xenopus tissue, since both our 3D and 2D tests involve disruption of links between cell layers. Another possible explanation for long-range activin signaling through a tissue is a relay mechanism by which activin reaches receiving cells located only at short distance from the source. Further propagation 
would then take place by activin secretion from these stimulated receiving cells. Previous work has shown that cells expressing constitutively active type I receptors do not secrete mesoderm-inducing factors (Jones et al. 1996). This observation suggests that relay mechanisms are unlikely in long-range activin signaling but do not exclude a relay mechanism that is ActRI independent. Our results using Follistatin or cell culture supernatant indicate that cells receiving activin are unlikely to secrete any mesoderm-inducing factors. Moreover, long-range activin signaling requires functional ActRII in receiving cells (McDowell et al. 1997). Altogether these results strongly support the argument against a relay mechanism in morphogen gradient propagation and interpretation in the early Xenopus embryo.

\section{Materials and methods}

\section{Reagents and $c D N A$}

All fluorescent probes are from Molecular Probes. Human Activin A is from R\&D Systems. MG132 is from Calbiochem. Streptavidin-HRPO, Immunopure Immobilized Streptavidin, and EZ-Link Sulfo-NHS-LC-Biotin are from Pierce. Anti-mouse HRPO and Anti-rabbit HRPO are from Amersham Biosciences. All other reagents are from Sigma. hTnfR cDNA is from K. Dassler (Institut für Klinische Chemie und Pathobiochemie, Universitatsklinikum Benjamin Franklin, Freie Universitat Berlin, Berlin, Germany). HDynamin K44E is from L. Jan (Graduate Group in Biophysics, University of California at San Francisco, San Francisco, CA). GFP-GPI, Rab7Q67L, GFP-Rab5, and Rab5 QL are from J. Smith (Wellcome Trust/Cancer Research UK Gurdon Institute, University of Cambridge, Henry Wellcome Building of Cancer and Developmental Biology, Cambridge, UK). mSmad7 is from S. Ohnuma (Department of Oncology, The Hutchinson/MRC Research Centre, University of Cambridge, Cambridge, UK). Smurf1 and Smurf2 are from K. Miyazono (Department of Molecular Pathology, Graduate School of Medicine, The University of Tokyo, Bunkyo-ku, Tokyo, Japan). hAlk4-HA and mActRIIB-Myc are from M. Whitman (Department of Cell Biology, Harvard Medical School, Boston, MA). mMycActRIIB is from W. Vale (Clayton Foundation Laboratories for Peptide Biology, Salk Institute for Biological Studies, La Jolla, CA). Xenopus Activin $\beta$ B is from D. Melton (Howard Hughes Medical Institute and Department of Molecular and Cellular Biology, Harvard University, Cambridge, MA). HA-ActRI has been constructed by inserting an HA epitope tag between $\mathrm{Met}^{30}$ and $\mathrm{Cys}^{31}$ of x Alk4.

\section{Cell surface biotinylation}

Animal cap cells were dissociated, chilled to $4^{\circ} \mathrm{C}$, and incubated at this temperature for $45 \mathrm{~min}$ in $\mathrm{MBS} 1 \times \mathrm{Ca} / \mathrm{Mg}$-free that contains $1 \mathrm{mg} / \mathrm{mL}$ sulfo NHS-LC biotin. After biotinylation, cells were washed four times in dissociation buffer supplemented with $1 \mathrm{mM}$ lysine to wash out and quench excess biotin.

\section{Receptors internalization tests}

Animal cap cells containing TnfR, xHA-Alk4, and Myc-ActRIIB mRNAs were collected and dissociated. Cells were chilled to $4^{\circ} \mathrm{C}$ and all the labeling steps were then carried out at this temperature as described (Di Guglielmo et al. 2003). Where triple labeling experiments were carried out, the following fluorophores were used: GFP label for subcellular compartment, Alexa 594-labeled antibody (or Transferrin), and Alexa 647-labeled antibody for receptor labeling. After labeling, cells were shifted to $23^{\circ} \mathrm{C}$ for different periods of time to allow trafficking to occur. At the end of the experiment, cells were fixed for 10 min in fixation medium (MBS $1 \times ; 3.7 \%$ formaldehyde; $3 \%$ sucrose) and processed for confocal analysis.

\section{Activin biotinylation}

hActivin and sulfo NHS-LC-Biotin were mixed in PBS for $2 \mathrm{~h}$ at $4^{\circ} \mathrm{C}$. Excess biotin was removed by dialysis against PBS and purified on SoftLink Resin (Promega), as described by manufacturer.

\section{Activin spreading tests}

$2 D$ test: This technique is fully described in a submitted manuscript (T. Kinoshita, J. Jullien, and J.B. Gurdon, in prep.). Briefly, caps are collected and placed up side down on a layer of MBS $1 \%$ agarose. A $36 \mathrm{nM}$ Activin bead is then placed in the middle of the cap and a piece of rhodamine-dextran-labeled animal cap is grafted next to it (Fig. 6C). A 1\% agarose-coated 6-mm coverslip is then placed on top of the system to prevent rounding of the cap. Animal caps are then incubated at $23^{\circ} \mathrm{C}$ for $4 \mathrm{~h}$ to allow diffusion of activin through the tissue. Animal caps are then fixed in MEMFA and processed for in situ hybridization.

$3 D$ test: Sandwiches of embryonic tissue are made by intercalating a layer of Dynamin K44E-injected animal cap cells between an uninjected animal cap and an activin-injected vegetal pole (Fig. 6A). Sandwiches are incubated at $23^{\circ} \mathrm{C}$ for $4 \mathrm{~h}$ to allow diffusion of activin through sandwiches, and then processed for in situ hybridization.

\section{RNA synthesis and injection}

Capped mRNAs were synthesized using a Megascript kit (Ambion). Embryos were in vitro fertilized, dejelled in MBS $0.1 \times 2 \%$ L-cystein hydrochlorite PH8, and placed in MBS $1 \times 4 \%$ Ficoll prior to injection.

\section{RT-PCR analysis}

mRNAs were extracted using the RNeasy mini kit (QIAGEN). Polymerase chain reactions with reverse transcription assays were carried out as described (Wilson and Melton 1994).

\section{Microscopy}

Confocal analysis was carried out on a Nikon Eclipse E800 microscope coupled to a Bio-Rad MRC1024 upright confocal unit. A $40 \times / 1.30$ oil DIC plan fluor objective was used for image capture. The Lasersharp 20005.2 software (Bio-Rad) was used for data acquisition.

\section{Acknowledgments}

We are very grateful to professor $\mathrm{T}$. Kinoshita for help with the 2D test analysis of gradient formation and to Dr. M. Robinson for helpful comments on the manuscript. 


\section{References}

Belenkaya, T.Y., Han, C., Yan, D., Opoka, R.J., Khodoun, M., Liu, H., and Lin, X. 2004. Drosophila dpp morphogen movement is independent of dynamin-mediated endocytosis but regulated by the glypican members of heparan sulfate proteoglycans. Cell 119: 231-244.

Bourillot, P.Y., Garrett, N., and Gurdon, J.B. 2002. A changing morphogen gradient is interpreted by continuous transduction flow. Development 129: 2167-2180.

Di Guglielmo, G.M., Le Roy, C., Goodfellow, A.F., and Wrana, J.L. 2003. Distinct endocytic pathways regulate TGF- $\beta$ receptor signalling and turnover. Nat. Cell Biol. 5: 410-421.

Dubois, L., Lecourtois, M., Alexandre, C., Hirst, E., and Vincent, J.P. 2001. Regulated endocytic routing modulates wingless signaling in Drosophila embryos. Cell 105: 613-624.

Dyson, S. and Gurdon, J.B. 1998. The interpretation of position in a morphogen gradient as revealed by occupancy of activin receptors. Cell 93: 557-568.

Ehrlich, M., Shmuely, A., and Henis, Y.I. 2001. A single internalization signal from the di-leucine family is critical for constitutive endocytosis of the type II TGF- $\beta$ receptor. J. Cell Sci. 114: 1777-1786.

Entchev, E.V., Schwabedissen, A., and Gonzalez-Gaitan, M. 2000. Gradient formation of the TGF- $\beta$ homolog Dpp. Cell 103: 981-991.

Green, J.B., New, H.V., and Smith, J.C. 1992. Responses of embryonic Xenopus cells to activin and FGF are separated by multiple dose thresholds and correspond to distinct axes of the mesoderm. Cell 71: 731-739.

Gurdon, J.B. and Bourillot, P.Y. 2001. Morphogen gradient interpretation. Nature 413: 797-803.

Harfe, B.D., Scherz, P.J., Nissim, S., Tian, H., McMahon, A.P., and Tabin, C.J. 2004. Evidence for an expansion-based temporal Shh gradient in specifying vertebrate digit identities. Cell 118: 517-528.

Hayes, S., Chawla, A., and Corvera, S. 2002. TGF $\beta$ receptor internalization into EEA1-enriched early endosomes: Role in signaling to Smad2. J. Cell Biol. 158: 1239-1249.

Henley, J.R., Krueger, E.W., Oswald, B.J., and McNiven, M.A. 1998. Dynamin-mediated internalization of caveolae. J. Cell Biol. 141: 85-99.

Inman, G.J., Nicolas, F.J., Callahan, J.F., Harling, J.D., Gaster, L.M., Reith, A.D., Laping, N.J., and Hill, C.S. 2002. SB-431542 is a potent and specific inhibitor of transforming growth factor- $\beta$ superfamily type I activin receptor-like kinase (ALK) receptors ALK4, ALK5, and ALK7. Mol. Pharmacol. 62: 65-74.

Jones, C.M., Armes, N., and Smith, J.C. 1996. Signalling by TGF- $\beta$ family members: Short-range effects of Xnr-2 and BMP-4 contrast with the long-range effects of activin. Curr. Biol. 6: $1468-1475$.

Kuruvilla, R., Zweifel, L.S., Glebova, N.O., Lonze, B.E., Valdez, G., Ye, H., and Ginty, D.D. 2004. A neurotrophin signaling cascade coordinates sympathetic neuron development through differential control of TrkA trafficking and retrograde signaling. Cell 118: 243-255.

Lee, M.A., Heasman, J., and Whitman, M. 2001. Timing of endogenous activin-like signals and regional specification of the Xenopus embryo. Development 128: 2939-2952.

Lin, H.K., Bergmann, S., and Pandolfi, P.P. 2004. Cytoplasmic PML function in TGF- $\beta$ signalling. Nature 431: 205-211.

Lo, R.S. and Massague, J. 1999. Ubiquitin-dependent degradation of TGF- $\beta$-activated smad2. Nat. Cell Biol. 1: 472-478.

Lu, Z., Murray, J.T., Luo, W., Li, H., Wu, X., Xu, H., Backer, J.M., and Chen, Y.G. 2002. Transforming growth factor $\beta$ acti- vates Smad2 in the absence of receptor endocytosis. J. Biol. Chem. 277: 29363-29368.

Marchant, L., Linker, C., and Mayor, R. 1998. Inhibition of mesoderm formation by follistatin. Dev. Genes Evol. 208: 157160.

McDowell, N., Zorn, A.M., Crease, D.J., and Gurdon, J.B. 1997. Activin has direct long-range signalling activity and can form a concentration gradient by diffusion. Curr. Biol. 7: 671-681.

Mukhopadhyay, A., Barbieri, A.M., Funato, K., Roberts, R., and Stahl, P.D. 1997. Sequential actions of Rab5 and Rab7 regulate endocytosis in the Xenopus oocyte. I. Cell Biol. 136: $1227-1237$.

Osada, S.I., Saijoh, Y., Frisch, A., Yeo, C.Y., Adachi, H., Watanabe, M., Whitman, M., Hamada, H., and Wright, C.V. 2000. Activin/nodal responsiveness and asymmetric expression of a Xenopus nodal-related gene converge on a FAST-regulated module in intron 1. Development 127: 2503-2514.

Piccolo, S., Agius, E., Leyns, L., Bhattacharyya, S., Grunz, H., Bouwmeester, T., and De Robertis, E.M. 1999. The head inducer Cerberus is a multifunctional antagonist of Nodal, BMP and Wnt signals. Nature 397: 707-710.

Piepenburg, O., Grimmer, D., Williams, P.H., and Smith, J.C. 2004. Activin redux: Specification of mesodermal pattern in Xenopus by graded concentrations of endogenous activin B. Development 131: 4977-4986.

Raiborg, C., Rusten, T.E., and Stenmark, H. 2003. Protein sorting into multivesicular endosomes. Curr. Opin. Cell Biol. 15: 446-455.

Ramirez-Weber, F.A. and Kornberg, T.B. 1999. Cytonemes: Cellular processes that project to the principal signaling center in Drosophila imaginal discs. Cell 97: 599-607.

Schohl, A. and Fagotto, F. 2002. $\beta$-Catenin, MAPK and Smad signaling during early Xenopus development. Development 129: $37-52$.

Seto, E.S., Bellen, H.J., and Lloyd, T.E. 2002. When cell biology meets development: Endocytic regulation of signaling pathways. Genes \& Dev. 16: 1314-1336.

Shi, Y. and Massague, J. 2003. Mechanisms of TGF- $\beta$ signaling from cell membrane to the nucleus. Cell 113: 685-700.

Tsukazaki, T., Chiang, T.A., Davison, A.F., Attisano, L., and Wrana, J.L. 1998. SARA, a FYVE domain protein that recruits Smad2 to the TGF $\beta$ receptor. Cell 95: 779-791.

van der Bliek, A.M., Redelmeier, T.E., Damke, H., Tisdale, E.J., Meyerowitz, E.M., and Schmid, S.L. 1993. Mutations in human dynamin block an intermediate stage in coated vesicle formation. J. Cell Biol. 122: 553-563.

van Kerkhof, P., Alves dos Santos, C.M., Sachse, M., Klumperman, J., Bu, G., and Strous, G.J. 2001. Proteasome inhibitors block a late step in lysosomal transport of selected membrane but not soluble proteins. Mol. Biol. Cell 12: 2556 2566.

Vecchione, A., Marchese, A., Henry, P., Rotin, D., and Morrione, A. 2003. The Grb10/Nedd4 complex regulates ligandinduced ubiquitination and stability of the insulin-like growth factor I receptor. Mol. Cell. Biol. 23: 3363-3372.

Wilson, P.A. and Melton, D.A. 1994. Mesodermal patterning by an inducer gradient depends on secondary cell-cell communication. Curr. Biol. 4: 676-686.

Zhang, L., Zhou, H., Su, Y., Sun, Z., Zhang, H., Zhang, Y., Ning, Y., Chen, Y.G., and Meng, A. 2004. Zebrafish Dpr2 inhibits mesoderm induction by promoting degradation of nodal receptors. Science 306: 114-117.

Zhu, A.J. and Scott, M.P. 2004. Incredible journey: How do developmental signals travel through tissue? Genes \& Dev. 18: 2985-2997. 


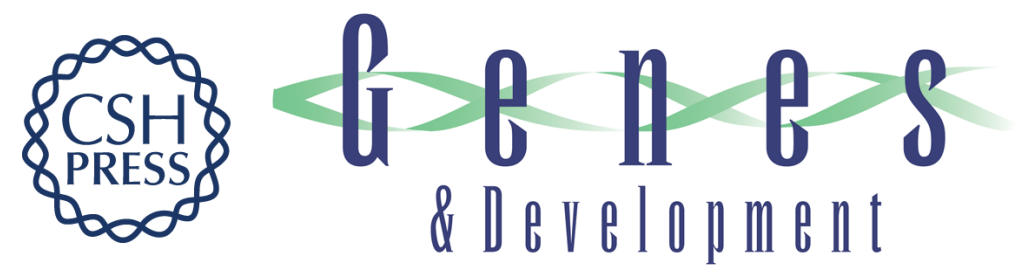

\section{Morphogen gradient interpretation by a regulated trafficking step during ligand-receptor transduction}

Jerome Jullien and John Gurdon

Genes Dev. 2005, 19:

Access the most recent version at doi:10.1101/gad.341605

\section{Supplemental http://genesdev.cshlp.org/content/suppl/2005/10/31/gad.341605.DC1 Material}

Related Content

Remember That Gradient?

Sci. STKE November , 2005 2005: tw420

References This article cites 37 articles, 17 of which can be accessed free at: http://genesdev.cshlp.org/content/19/22/2682.full.html\#ref-list-1

Articles cited in:

http://genesdev.cshlp.org/content/19/22/2682.full.html\#related-urls

\section{License}

Email Alerting

Receive free email alerts when new articles cite this article - sign up in the box at the top Service

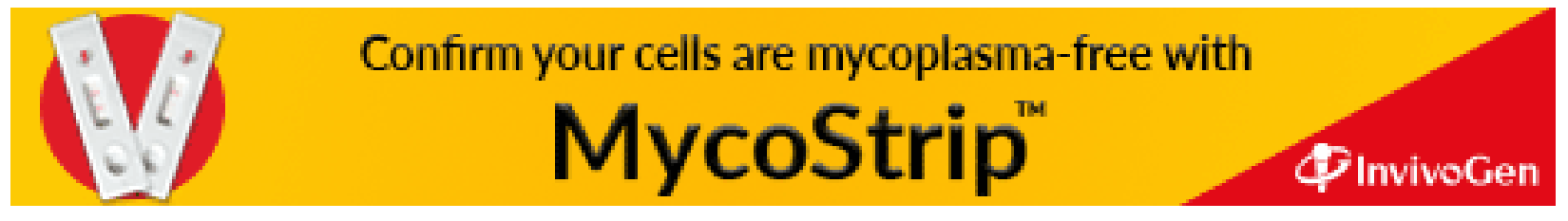

